\title{
Intersecting Pandemics of HIV and SARS-CoV-2: Commentary on the Special Issue
}

\author{
Sten H. Vermund ${ }^{1}$ \\ Published online: 22 February 2022 \\ (c) The Author(s), under exclusive licence to Springer Science+Business Media, LLC, part of Springer Nature 2022
}

\begin{abstract}
Purpose of Review This editorial introduces this special Global Health Section on the interface of the HIV/AIDS and COVID-19 pandemics.

Recent Findings Authors of articles in this special issue take on a variety of topics that capture how the acute COVID19 pandemic affected global efforts towards HIV control, and how co-infection, stigma, and social determinants of disease have affected populations on multiple continents.

Summary Two historic pandemics -- HIV/AIDS and COVID-19 -- have affected the world in our lifetimes at a level reminiscent of the 1918-1919 H1N1 influenza pandemic. We have much to learn from both experiences to optimize pandemic disease control, prevention, and management.
\end{abstract}

Keywords HIV $\cdot$ COVID-19 $\cdot$ Pandemic $\cdot$ Epidemic $\cdot$ SARS-CoV-2 $\cdot$ Social determinants

The major pandemics of our lifetimes have been HIV/AIDS, first recognized in 1981 and now endemic in all the world's populated continents, and COVID-19, emerging in late 2019 as a respiratory viral pandemic. HIV is spread via sexual, parenteral, and perinatal routes; growth in the pandemic has been gradual and steady, disproportionately affecting especially vulnerable subgroups. Clinical AIDS appeared years after HIV infection had occurred. With declining HIV incidence rates in most (but not all) regions of the globe, the pandemic may be considered to have reached an endemic state.

SARS-CoV-2, in contrast, was a respiratory pathogen spread in a world of global travel and high-density urbanized living. Both viral infectious diseases were neglected at policy levels, presented disparities in impact based on social determinants of disease, had prominent political

This article is part of the Topical Collection on The Global Epidemic

Sten H. Vermund

sten.vermund@yale.edu

1 Yale School of Public Health, New Haven, CT, USA and even scientific leaders who were hostile towards selected prevention measures, and experienced partisan anti-science, stigma-driven policies. These two defining modern pandemics have major differences and surprising similarities that have inspired this 2022 Global Epidemic issue of Current HIV/AIDS Reports. Their origins are both from zoonotic RNA viruses. Emotional and partisan sentiments have inhibited effective control efforts in both cases. Pathogenic processes of both viruses have interesting similarities, as with the complex immune perturbations beyond the cellular infection and replication process itself, even as mechanisms differ. Stigma exists in society for both diseases, but HIV/ AIDS is steeped in homophobia and neglect of marginalized persons such as drug users and sex workers, while COVID-19 puts the neglected elderly and the impoverished at greatest risk. In a series of creative and multi-disciplinary articles, the authors of this global epidemic issue of Current HIV AIDS Reports seek to elucidate these contrasts, illustrating how lessons from the HIV/AIDS pandemic might be applied to the current COVID-19 pandemic caused by SARS-CoV-2.

HIV/AIDS emerged in 1981 at a time when its cause and its transmission dynamics were uncertain. Antiviral drug development was nascent, and knowledge of retroviruses 
had grown with discovery of human T-cell lymphotropic virus type 1 (HTLV-I) in humans [1] and research into retroviruses in non-human primates and felines, among others. With an understanding of the sexual and parenteral transmission dynamics, political backlash in the USA and other nations led to harsh assessments of vulnerable and infected persons. This prejudice extended to persons of all gender identities and ages, as the infamous community hostility to the family of Ryan White, a boy living with hemophilia and HIV infection in the USA, demonstrated [2]. Most persons afflicted early in the HIV pandemic were men who had sex with men (MSM), both with or without a same-sex sexual orientation identity; persons who injected drugs (PWID); persons with multiple sexual partners without condom use, and; persons who acquired infection from other sources (e.g., heterosexual, perinatal or breastfeeding, needle-stick, blood and blood products) [3]. Extraordinary progress in antiretroviral drug development turned a once-lethal disease into a chronic, manageable one [4]. Yet, successful prevention has been elusive and today one might view HIV/AIDS as an endemic viral disease that may never be controlled short of a deployable and acceptable vaccine, not yet available after four decades of effort against the many subtypes of the virus [5, 6]. Stigma and discrimination continue to interfere with preventive and clinical care services [7]. While progress against stigma has been made globally, discriminatory laws and policies against same-sex relationships illustrate the immense challenges remaining [8].

COVID-19 emerged in 2019, fully 16 years after the 2003-2004 severe acute respiratory syndrome (SARS) pandemic that announced to the world the lethal potential of bat-origin coronaviruses in humans [9]. While four prior coronaviruses had been identified in humans, they caused a disease like the common cold or mild influenza [10]; none was as serious as the viral respiratory disease caused by a SARS-associated coronavirus (SARS-CoV) that had a $10 \%$ case-fatality rate. The Middle East respiratory syndrome (MERS)-related coronavirus (EMC/2012) emerged in 2012 and while less infectious, was even more lethal with an over $32 \%$ case-fatality rate [11]. Global spread of the novel coronavirus was facilitated by modern air travel and globalized business relationships [12]. As with other RNA viruses, emerging variants are protean and modified considerably the population dynamics of viral spread, including the efficiency of vaccine protection [13]. Yet again, the specter of discrimination and stigma emerged in many ways, including racial profiling $[14,15]$. Persons getting infected and ill might be viewed as a careless or biologically weak. Persons seeking to prevent infection with mask use or vaccination might find conflict with persons not taking such precautions. Public health professionals might be seen as taking a partisan view weighing individual liberties in favor of societal welfare.

COVID-19 has generated divisive sentiments against selected sub-populations, as did AIDS. The most flagrant example is the sentiment expressed in diverse circles suggesting that higher risk among the elderly was a legitimate price to pay for the rest of society tolerating infections and preserving economic business-as-usual $[16,17]$. Ageism was yet a new form of bias in the control of COVID19 , potentially as lethal as the neglect of populations at disproportionate risk for HIV [18]. In some political circles, benign approaches to COVID-19 risk reduction such as masks/face coverings [19] became as controversial as condoms to prevent HIV [20]. Even with the availability of safe and effective coronavirus vaccines in late 2020, anti-science sentiments from burgeoning anti-vaccination movements made partisan the public health efforts towards universal immunization in diverse nations such as the USA or Brazil [21•, 22•, 23•, 24].

Given differences and synergies in experiences across these pandemics, this issue of Current HIV AIDS Reports tackles an amazing array of topics. Biological comparisons and interactions are described [25]. Clinical interactions $[26,27]$ and service disruptions from COVID-19 lockdowns $[28,29]$ are addressed. Social and behavior contributors and consequences are reviewed [30,31]. Global challenges in different continents and regions are presented [32-35]. The use of modeling and forecasting is discussed [36]. Finally, how HIV vaccine research helped us in the search for a SARS-CoV-2 vaccine is revealed [37], building upon the molecular elucidation of the SARS-CoV genome and viral entry into host cells through the spike glycoprotein (S-glycoprotein) interaction with the angiotensin-converting enzyme 2 (ACE2) cellular receptor [38]. Editor-in-Chief Paul Volberding and I feel that this global issue will be of interest to many, particularly investigators and health workers who pivoted from viral control work in other arenas (like HIV/AIDS) to COVID-19 in 2019-2021, seeking to confront the new pandemic threat [39].

Funding The author is supported by the National Institutes of Health grants P30MH062294 and UM1AI068619.

\section{Declarations}

Conflict of Interest The author declares no competing interests.

Human and Animal Rights and Informed Consent This article does not contain any studies with human or animal subjects performed by the author. 


\section{References}

Papers of particular interest, published recently, have been highlighted as:

- Of importance

1. Gallo RC, Montagnier L. The discovery of HIV as the cause of AIDS. N Engl J Med. 2003;349(24):2283-5. https://doi.org/10. 1056/NEJMp038194.

2. Health Resources \& Services Administration. About the Ryan White HIV/AIDS Program/Who was Ryan White? October 2016. https://hab.hrsa.gov/about-ryan-white-hivaids-program/ who-was-ryan-white, accessed December 28, 2021

3. De Cock KM, Jaffe HW, Curran JW. Reflections on 40 years of AIDS. Emerg Infect Dis. 2021;27(6):1553-60. https://doi.org/ 10.3201/eid2706.210284.

4. Saag MS, Gandhi RT, Hoy JF, et al. Antiretroviral drugs for treatment and prevention of HIV infection in adults: 2020 recommendations of the International Antiviral Society-USA Panel. JAMA. 2020;324(16):1651-69. https://doi.org/10.1001/jama. 2020.17025 .

5. Shapiro SZ. Lessons for general vaccinology research from attempts to develop an HIV vaccine. Vaccine. 2019;37(26):34008. https://doi.org/10.1016/j.vaccine.2019.04.005.

6. Hemelaar J, Elangovan R, Yun J, et al. Global and regional epidemiology of HIV-1 recombinants in 1990-2015: a systematic review and global survey. Lancet HIV. 2020;7(11):e772-81. https://doi.org/10.1016/S2352-3018(20)30252-6.

7. Armoon B, Higgs P, Fleury MJ, et al. Socio-demographic, clinical and service use determinants associated with HIV related stigma among people living with HIV/AIDS: a systematic review and meta- analysis. BMC Health Serv Res. 2021;21(1):1004. https://doi.org/10.1186/s12913-021-06980-6.

8. Beyrer C, Baral SD, Collins C, et al. The global response to HIV in men who have sex with men. Lancet. 2016;388(10040):198206. https://doi.org/10.1016/S0140-6736(16)30781-4.

9. Song Z, Xu Y, Bao L, et al. From SARS to MERS, thrusting coronaviruses into the spotlight. Viruses. 2019;11(1):59. https:// doi.org/10.3390/v11010059.

10. Fung TS, Liu DX. Human coronavirus: host-pathogen interaction. Annu Rev Microbiol. 2019;8(73):529-57. https://doi.org/ 10.1146/annurev-micro-020518-115759.

11. Vergara-Alert J, Vidal E, Bensaid A, Segalés J. Searching for animal models and potential target species for emerging pathogens: experience gained from Middle East respiratory syndrome (MERS) coronavirus. One Health. 2017;3(3):34-40. https://doi. org/10.1016/j.onehlt.2017.03.001.

12. Khattab NM, Vermund SH, Hu Y. How coronavirus disease 2019 entered Africa and the Middle East: a case study from Egypt. Trans R Soc Trop Med Hyg. 2020;114(10):715-7. https://doi. org/10.1093/trstmh/traa065.

13. Lucas C, Vogels CBF, Yildirim I, et al. Impact of circulating SARS-CoV-2 variants on mRNA vaccine-induced immunity. Nature. 2021;600(7889):523-9. https://doi.org/10.1038/ s41586-021-04085-y.

14. Cho H, Li W, Cannon J, Lopez R, Song CC. Testing three explanations for stigmatization of people of Asian descent during COVID-19: maladaptive coping, biased media use, or racial prejudice? Ethn Health. 2021;26(1):94-109. https://doi.org/10. 1080/13557858.2020.1830035.

15. The Associated Press. Texas Lt. Gov. Dan Patrick's COVID claim denounced as racist: Texas' lieutenant governor is blaming unvaccinated Black people for rising COVID-19 hospitalization and death rates. Associated Press/US News and World
Report, 2021, https://www.usnews.com/news/best-states/ texas/articles/2021-08-20/dan-patrick-blames-unvaccinat ed-black-people-for-covid-surge

16. Adrianna Rodriguez. Texas' lieutenant governor suggests grandparents are willing to die for US economy. USA TODAY, 2020, https://www.usatoday.com/story/news/nation/2020/03/24/covid19-texas-official-suggests-elderly-willing-die-economy/29059 90001/

17. D'cruz M, Banerjee D. 'An invisible human rights crisis': the marginalization of older adults during the COVID-19 pandemic - an advocacy review. Psychiatry Res. 2020;292:113369. https:// doi.org/10.1016/j.psychres.2020.113369.

18. Levy BR, Slade MD, Chang ES, Kannoth S, Wang SY. Ageism amplifies cost and prevalence of health conditions. Gerontologist. 2020;60(1):174-81. https://doi.org/10.1093/geront/gny131.

19. Abaluck J, Chevalier JA, Christakis NA, et al. The case for universal cloth mask adoption and policies to increase the supply of medical masks for health workers. Covid Economics (CEPR Press) 2020; Issue 5 (16 April 2020): 147-159 (https://cepr.org/ sites/default/files/news/CovidEconomics5.pdf). Pre-print: Abaluck J, Chevalier JA, Christakis NA, et al. The case for universal cloth mask adoption and policies to increase supply of medical masks for health workers (April 1, 2020). Available at SSRN: https://ssrn. com/abstract=3567438 or https://doi.org/10.2139/ssrn.3567438.

20. Haberer JE, van der Straten A, Safren SA, et al. Individual health behaviours to combat the COVID-19 pandemic: lessons from HIV socio-behavioural science. J Int AIDS Soc. 2021;24(8):e25771. https://doi.org/10.1002/jia2.25771.

21.• James EK, Bokemper SE, Gerber AS, Omer SB, Huber GA. Persuasive messaging to increase COVID-19 vaccine uptake intentions. Vaccine. 2021;39(49):7158-65. https://doi.org/10. 1016/j.vaccine.2021.10.039. One might anticipate similar challenges in public communication when an HIV vaccine is finally available for global distribution.

22. Solís Arce JS, Warren SS, Meriggi NF, et al. COVID-19 vaccine acceptance and hesitancy in low- and middle-income countries. Nat Med. 2021;27(8):1385-94. https://doi.org/10.1038/s41591021-01454-y. Residents of low- and middle-income nations may also be under the sway of anti-vaccine forces. Understanding the diversity of community sentiments is vital for all vaccine-preventable diseases.

23. Loomba S, de Figueiredo A, Piatek SJ, de Graaf K, Larson HJ. Measuring the impact of COVID-19 vaccine misinformation on vaccination intent in the UK and USA. Nat Hum Behav. 2021;5(3):337-48. https://doi.org/10.1038/s41562-021-010561. High income nations such as the UK and the US have had suboptimal vaccine coverage, despite no shortages of vaccine or distribution points. We can expect even greater challenges in less well resourced areas.

24. Schoch-Spana M, Brunson EK, Long R, et al. The public's role in COVID-19 vaccination: human-centered recommendations to enhance pandemic vaccine awareness, access, and acceptance in the United States. Vaccine. 2021;39(40):6004-12. https://doi. org/10.1016/j.vaccine.2020.10.059.

25. Immunology of chronic HIV and acute SARS-CoV-2 co-infection: theoretical and experimental findings. Akiko Iwasaki (Yale School of Medicine)

26. Clinical findings among HIV and SARS-CoV-2 co-infected persons. Jordi Casabona (CEESCAT, Barcelona)

27. Maternal and newborn outcomes of COVID-19 and pregnancy: parallels and contrasts with HIV. Dan Li (Yale School of Public Health)

28. Disruptions of HIV and tuberculosis services in a COVID-19 pandemic lockdown: the South African experience. Quarraisha Abdool Karim (CAPRISA, Durban) 
29. Socioeconomic burdens of concurrent acute COVID-19 and chronic HIV disease in vulnerable LMIC populations. Lyle McKinnon (U. of Manitoba)

30. Psychosocial issues in COVID-19 among PLHIV. Seth Kalichman (U. of Connecticut)

31. Social determinants of disease: contrasting HIV and COVID-19 experiences. Paula Frew (UNLV School of Public Health and UNLV Population Health \& Health Equity Initiative)

32. Integration of HIV and COVID-19 services in Africa: how did PEPFAR pivot? George Siberry (USAID) with African authors

33. HIV and COVID-19 in Latin America. Patricia Garcia (UPCH, Lima)

34. COVID-19 presentation among HIV-infected persons in China. Yifei Hu (CCMU, Beijing)

35. Challenges in Asia and its special populations. Kamarulzaman

36. Mathematical modeling of COVID-19: lessons from HIV forecasting. Gregg Gonsalves (Yale School of Public Health)
37. Vaccines for COVID-19: How has our experience with HIV research informed SARS-CoV-2 work? Kayvon Modjarrad (Emerging Infectious Diseases Branch, Walter Reed Army Institute of Research)

38. Lu R, Zhao X, Li J, et al. Genomic characterisation and epidemiology of 2019 novel coronavirus: implications for virus origins and receptor binding. Lancet. 2020;395(10224):565-74. https:// doi.org/10.1016/S0140-6736(20)30251-8.

39. Fauci A. Victories against AIDS have lessons for COVID19. Nature. 2021;600(7887):9. https://doi.org/10.1038/ d41586-021-03569-1.

Publisher's Note Springer Nature remains neutral with regard to jurisdictional claims in published maps and institutional affiliations. 